www.nature.com/pj

\title{
Microcellular foaming of PP/EPDM/organoclay nanocomposites: the effect of the distribution of nanoclay on foam morphology
}

\author{
Mohsen Keramati, Ismail Ghasemi, Mohammad Karrabi and Hamed Azizi
}

In this study, microcellular foams based on polypropylene/ethylene propylene diene monomer/organoclay (PP/EPDM/organoclay) nanocomposites were produced via a batch process using supercritical nitrogen $\left(\mathrm{N}_{2}\right)$ as the physical blowing agent. The foaming temperature and morphological observation demonstrated that foaming occurred mostly in the PP phase. To evaluate the effect of organoclay distribution on the cell nucleation step and the final foam morphology, the location of the nanofillers in the nanocomposite blend was traced by means of surface energies and Young's equation. The calculated wetting coefficient predicted that the organoclays would have more affinity with PP and would primarily distribute into the PP phase. These results were confirmed by atomic force microscopy (AFM), dynamic mechanical thermal analysis (DMTA) and transmission electron microscopy (TEM). The cell density and average cell sizes are the main foam characteristics that were determined using SEM micrographs, and it was found that these parameters were influenced by the presence of nanoclays. An improved foam morphology was obtained in the nanocomposite samples.

Polymer Journal (2012) 44, 433-438; doi:10.1038/pj.2012.2; published online 15 February 2012

Keywords: microcellular foam; nanoclay distribution; nucleation; PP/EPDM

\section{INTRODUCTION}

Because polymeric materials are widely used in daily life, the need to reduce the amount of consumed materials has received significant attention. Currently, polymeric foams have become more popular because conventional foams exhibit two important limitations: weak mechanical properties and harmful residues. Hence, the idea of microcellular foaming was invented by Martini et al. ${ }^{1}$ at the Massachusetts Institute of Technology to produce lightweight materials without compromising their functional performance. Microcellular foams are defined as foams with cell populations $>10^{9}$ cells $\mathrm{cm}^{-3}$ and cell sizes of approximately $10 \mu \mathrm{m} .^{2}$ The tiny size and uniform distribution of bubbles, which are smaller than the critical flaws that already exist in polymers, make microcellular plastics possible for use in daily life applications instead of conventional foams. ${ }^{3}$

Microcellular foaming technology has been rapidly developed in the past 2 decades, and microcellular parts have been produced via batch, injection molding and extrusion processes. ${ }^{4-9}$ Despite a variety of production methods, the main foaming mechanism is the same. In the first step, the polymer is saturated with an inert gas at high pressure. In the second step, by means of rapid depressurization, the solubility of the dissolved gas decreases, and a super-saturation state occurs. As a result, cell nucleation is thermodynamically favored, and then microcells form through stabilization. ${ }^{8}$
Isotactic polypropylene is a semi-crystalline polymer with a wide range of applications due to its excellent cost/properties ratio. Blending PP with thermoplastic polyolefin elastomers (known as TPO), such as EPDM, could improve its toughness and impact behavior and make it more desirable for industrial applications, such as those in the automotive industry. ${ }^{10,11}$ Recently, some effort has been made to reduce the weight of this blend by microcellular foaming. ${ }^{12-14}$

Wong et al. studied the mechanical properties of microcellular TPO foams based on PP/EPR and found that the mechanical properties of microcellular TPO foams are directly related to the processing parameters. They showed that by achieving microcellular structure, the weight of TPO materials can be reduced without sacrificing much of the mechanical properties. ${ }^{12}$

It is well known that cell density and cell size are the most important characteristics of microcellular foams, and the majority of the studies of microcellular foams have been focused on increasing cell density and decreasing cell size ${ }^{15-17}$ More recently, the incorporation of nanoscaled additives has been considered to enhance cell nucleation and produce more bubbles with a finer morphology. ${ }^{16-21}$ Nanocellular foams have also been achieved in some cases. 22,23

Furthermore, the addition of nanofillers to polymers cause remarkable improvement in their properties, such as the modulus, strength, thermal stability and gas permeability resistance, compared with non- 
filled and microfilled ones. Nanocomposites based on polymeric blends were first introduced by Kamal et al. ${ }^{24}$ It has been shown that the use of inorganic nanofillers changes the blend morphology ${ }^{25}$ and the elastic properties of the blend, ${ }^{26}$ and they also act as compatibilizers in some immiscible polymer blends. ${ }^{27}$ Moreover, the distribution of nanoparticles in binary blends is the subject of most new research in the field. ${ }^{28-31}$ The location of nanofillers in each individual phase of the blends or at the interface can influence the final properties in different ways. Ashabi et al. ${ }^{29}$ showed by means of XRD, TEM and SEM measurements that in the blend of PA6 with SAN and ABS, the organoclay mostly localizes in the PA phase. Jacques et al. studied the morphological and rheological properties of $\mathrm{PE} / \mathrm{PA} /$ nanoclay blends and reported that when $\mathrm{PE}$ is the matrix, the nanoclays are located at the interface, and this leads to the reduction of the PA dispersed phase-size via coalescence inhibition. However, in the case of a PA matrix, nanoclays are located in both the PA phase and at the interphase. ${ }^{30}$

This work is motivated by the current researches in microcellular nanocomposite foams. ${ }^{32,33}$ As a new approach, the location of nanofiller was tracked in the blend phases using AFM, DMTA and surface parameters and then the effect of nanoclay distribution on the final foam morphology was discussed.

\section{EXPERIMENTAL PROCEDURE}

\section{Materials}

Polypropylene (PI0800) with MFI of $8 \mathrm{gr} / 10 \mathrm{~min}$ was supplied by Bandar Imam Petrochemical Co., Bandar Imam, Iran. EPDM with the trade name of KEP270 containing 57 wt $\%$ ethylene and $4.5 \mathrm{wt} \%$ ENB was manufactured by Kumho Polychem, Seoul, Korea. The nanoclay employed in this study was Cloisite 15A, a natural montmorillonite modified with dimethyl dehydrogenated tallow (2M2HT), a quaternary ammonium salt, from Southern Clay Inc., Gonzales, TX, USA. The initial gallery height $\left(d_{001}\right)$ was $31.5 \AA$. Maleic anhydride grafted polypropylene (PP-g-Ma) as a compatibilizer was manufactured by Priex 20070, Solvay, Brussels, Belgium. $\mathrm{N}_{2}$ gas with a purity of 99.9\% was purchased from a local market.

All materials were used as received, but the nanoclay was dried in a vacuum oven at $70^{\circ} \mathrm{C}$ for $6 \mathrm{~h}$ before processing.

\section{Nanocomposite preparation}

Compounding was performed by means of a Brabender internal mixer with a roller blade rotor (Plasticorder, Duisburg, Germany) operating at a rotor speed of 60 r.p.m. at $190{ }^{\circ} \mathrm{C}$.

PP was first fed into the mixing chamber, and EPDM was added after PP melting. The PP-g-MA and the nanoclay were incorporated into the compound after $2 \mathrm{~min}$, and mixing continued for $12 \mathrm{~min}$. After compounding, the samples were dumped out and pressed by a compression-molding machine (Toyoseki, Tokyo, Japan) at $200^{\circ} \mathrm{C}$ and $15 \mathrm{MPa}$ into 1 -mm thick sheets. The compositions of the samples are listed in Table 1.

\section{Microcellular foaming}

The quick heating method ${ }^{34}$ was used to foam the samples, using a homemade autoclave with an electrical heater covering. The samples were first saturated by $\mathrm{N}_{2}$ at 1400 PSI. High temperature was also chosen to achieve a shorter saturation time (approximately $2 \mathrm{~h}$ ). In the next step, a rapid pressure drop

Table 1 Compositions of samples

\begin{tabular}{lcccc}
\hline Sample & $P P(p h r)$ & EPDM(phr) & MA-PP(phr) & Cloisite $15 A(p h r)$ \\
\hline B1 & 50 & 50 & - & - \\
B2 & 50 & 50 & 5 & 2 \\
B3 & 50 & 50 & 5 & 4 \\
\hline
\end{tabular}

Abbreviations: EPDM, ethylene propylene diene monomer; PP, polypropylene. was imposed on the system, the samples were finally cooled by purging the chamber with cold nitrogen, and the foam cells were fixed. The cooling was performed as soon as depressurization was completed.

\section{Measurements}

The cellular structure of the foamed samples was studied by scanning electron microscopy (SEM), Tescan VEGA-II, Los Angeles, CA, USA. All of the samples were immersed in liquid nitrogen, and the cryogenically fractured surfaces were coated with gold. Unfoamed samples were etched by $\mathrm{n}$-heptane for $24 \mathrm{~h}$ to extract the EPDM phase. Some of the samples were analyzed in SEM backscattering mode (BSE), and the samples of the EPDM phase were stained with osmium tetroxide $\left(\mathrm{OSO}_{4}\right)$ for 2 weeks before the analysis. The cell density, $N_{\mathrm{f}}$, which is defined as the number of cells per cubic volume, can be calculated from Equation 1: ${ }^{35}$

$$
N f=\left(\frac{n M^{2}}{A}\right)^{3 / 2}
$$

where $n$ is the number of bubbles observed in the SEM micrograph, $A$ is the area of the picture $\left(\mathrm{cm}^{2}\right)$ and $M$ is the magnification factor.

The surface tension was measured by direct contact angle measurements using a model G10 instrument from KRUSS, Hamburg, Germany. PP and EPDM films, $70 \mu \mathrm{m}$ thick, and a compressed tablet of Cloisite $15 \mathrm{~A}$ were prepared for the surface tension measurements. The measurements were performed using the Wu method, and water and di-iodomethane were used as polar and nonpolar solvents, respectively.

Dynamic mechanical properties were studied using a DMA-TRITON, TRITEC 2000 instrument manufactured in England. Sheets of $1 \mathrm{~mm}$ thickness were heated from -100 to $100^{\circ} \mathrm{C}$ at a rate of $5{ }^{\circ} \mathrm{C}$ per min.

AFM measurements were performed using a Dualscope, DME atomic force microscope, manufactured in, Herlev, Denmark. The samples for AFM measurements were first microtomed, and scans were taken in tapping mode with an $\mathrm{AC}$ probe.

Transmission electron microscopy (TEM) was employed to characterize the nanocomposite structure. TEM measurements were performed on an EM 208 transmission electron microscope (Phillips, Amsterdam, Netherlands, Denmark) using an accelerating voltage of $100 \mathrm{kV}$. The AFM samples were first ultramicrotomed in liquid nitrogen with a diamond knife.

\section{RESULTS AND DISCUSSION}

To gain a better understanding of the blend morphology, SEM analysis was performed before foaming. Figure 1 shows the SEM micrograph

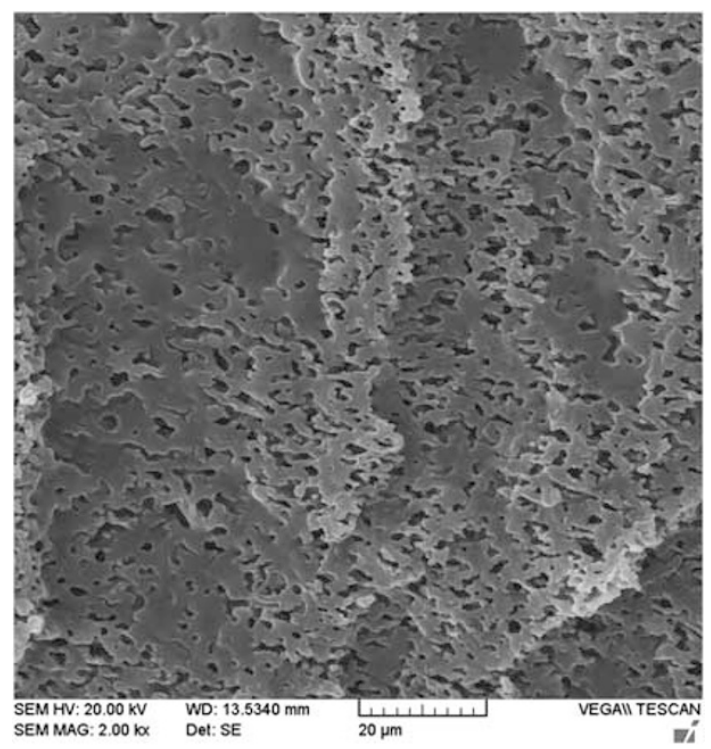

Figure 1 SEM micrograph of the fractured surface of sample B2. 
of the sample B2 fractured surface. In Figure 1, the dark regions are the EPDM extracted phase that was dispersed into the PP matrix. According to this micrograph, the blend morphology has a matrixdroplet morphology, and the fine EPDM droplets are dispersed into the PP matrix.

In the solid-state microcellular foaming process, the foaming temperature is a vital parameter, and choosing an incorrect temperature may lead to an undesirable foam structure or foaming may not even occur. The thermodynamic driving force for cell growth is $\left(T-T_{\mathrm{g}}\right)$, so the foaming temperature should be higher than the glass-transition temperature of the polymer. However, there is an upper limit for the foaming temperature beyond which the viscosity drops and the cellular structure collapses before stabilizing. ${ }^{36,37}$

Figure 2 shows SEM micrographs from the surface of the foamed samples that were foamed at different temperatures $(70,100,130$ and $150{ }^{\circ} \mathrm{C}$ ). No sign of foaming can be detected at 70 and $100^{\circ} \mathrm{C}$. Some scattered parts with the foaming structure are detected at $130^{\circ} \mathrm{C}$; however, a complete foam morphology with spherical cells was obtained at $150^{\circ} \mathrm{C}$. Both $70^{\circ} \mathrm{C}$ and $100^{\circ} \mathrm{C}$ are higher than the glass transition temperature of $\mathrm{PP}\left(\approx 5^{\circ} \mathrm{C}\right)$ and $\operatorname{EPDM}\left(\approx-50^{\circ} \mathrm{C}\right)$, but foaming did not occur at these temperatures. The reason for this lack of foaming can be described as follows: PP is a semi-crystalline polymer, and it is very difficult to be foamed because gases are not able to diffuse into the crystalline regions. At high-foaming temperatures (near the PP melting point), the crystalline parts could be partially or completely disrupted. Disruption of the crystal structures enable $\mathrm{N}_{2}$ to diffuse and dissolve into the PP matrix and facilitate foaming. It may be possible that foaming occurred in the PP phase. This is similar to what Mei et al. ${ }^{36}$ reported for the foaming conditions of PP with carbon dioxide. To clarify this hypothesis, Figure 3 shows the cryogenically fractured surface of an unfoamed sample (Figure 3a) and a foamed sample (Figure $3 \mathrm{~b}$ ) in BSE, which was stained with $\mathrm{OSO}_{4}$ to highlight the EPDM phase before analysis. Comparing Figure $3 \mathrm{a}$ with Figure 1 (etched one) demonstrates that the white domains in the BSE mode image are the EPDM dispersed phases. In Figure $3 \mathrm{~b}$ (the foamed sample), the three different zones are distinguishable. In the images, the dark holes are the foam bubbles, the white spots are related to EPDM domains and the gray regions are the PP matrix. Consequently, from the SEM micrographs of samples of different foaming temperatures and the BSE mode SEM images, it could be deduced that foaming has taken place in the PP phase.

According to classic nucleation theory, nanoclays act as nucleating agents, and by changing the nucleation mechanism from homogenous to heterogeneous, they reduce the nucleation-free energy and lead to more efficient foam nucleation. On the basis of this theory, the heterogeneous nucleation rate is given by: ${ }^{38}$

$$
N_{\text {het }}=f_{1} C_{1} \exp \left(\frac{-\Delta G_{\text {het }}}{\mathrm{KT}}\right)
$$

where $C_{1}$ is the nucleation site, $f_{1}$ is the frequency factor of the gasjoining nucleus, $K$ is the Boltzmann constant, $T$ is the absolute temperature and $\Delta G_{\text {het }}$ is the heterogeneous nucleation-free energy
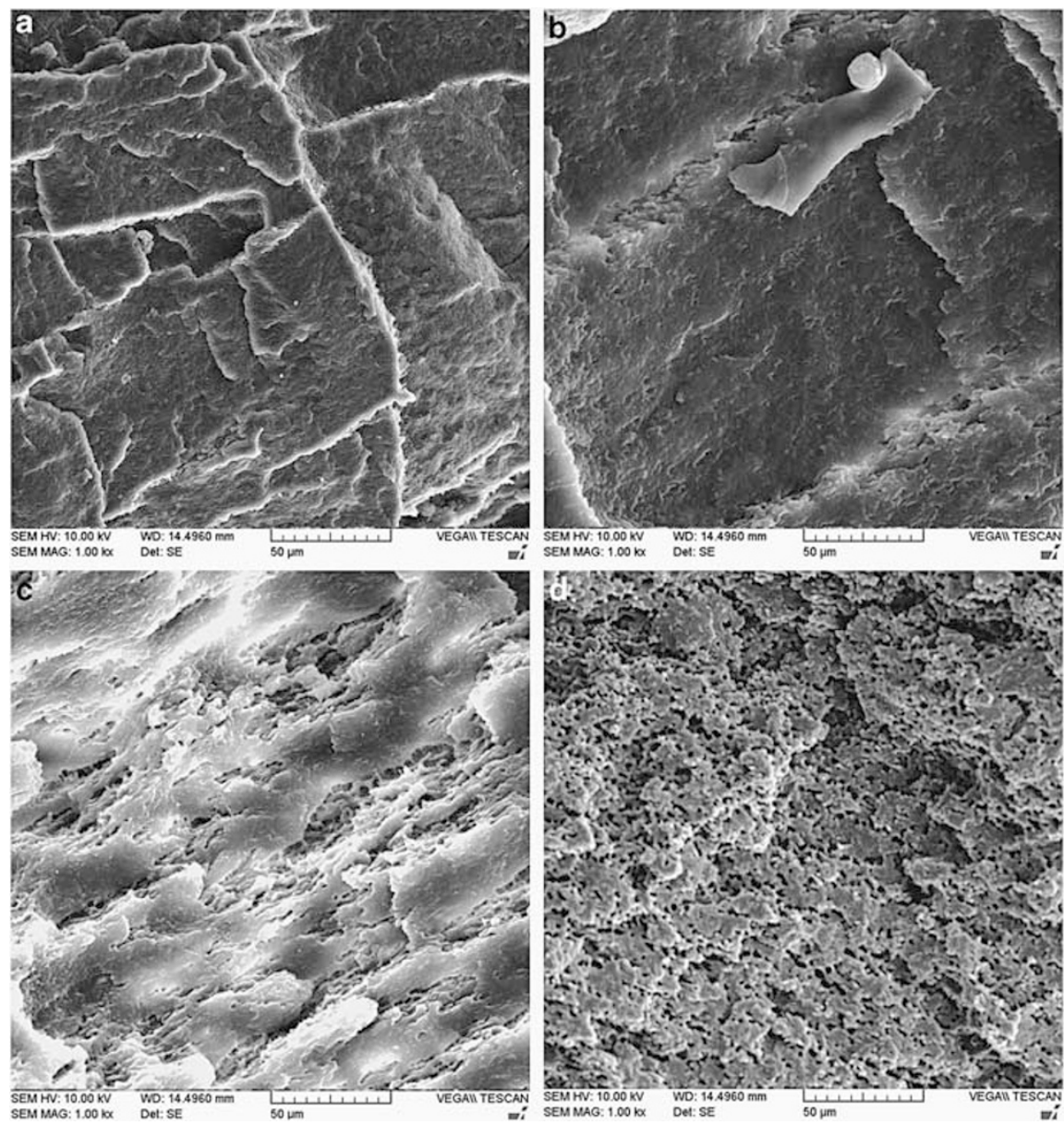

Figure $2 \mathrm{SEM}$ micrographs of foamed samples at different foaming temperatures: (a) $70^{\circ} \mathrm{C}$, (b) $100^{\circ} \mathrm{C}$, (c) $130^{\circ} \mathrm{C}$ and (d) $150^{\circ} \mathrm{C}$. 

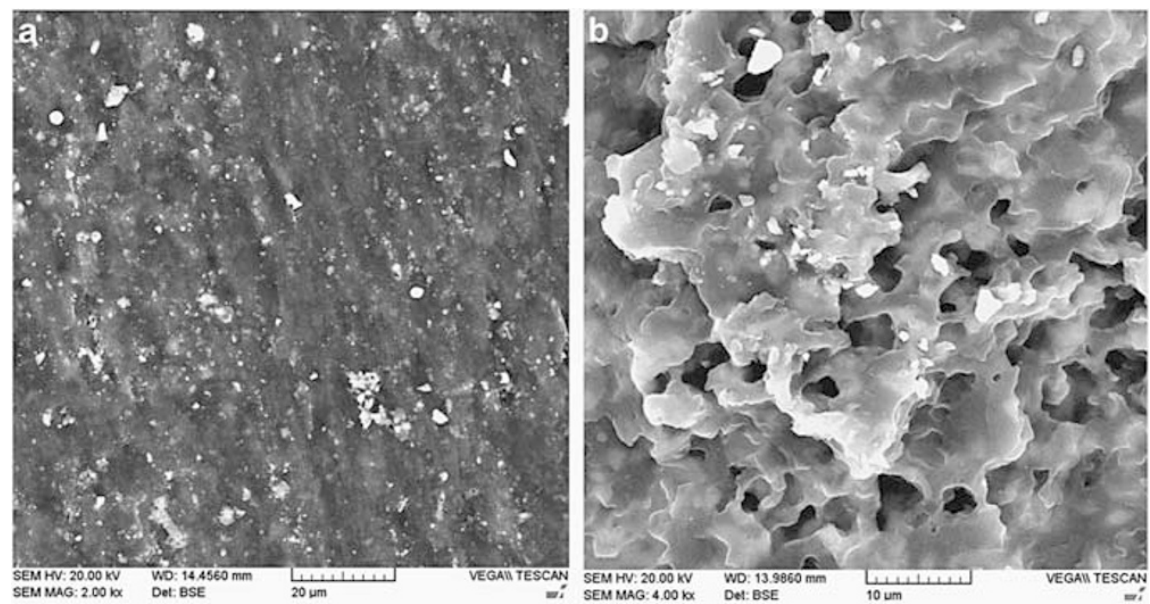

Figure 3 SEM micrographs of (a) an unfoamed sample and (b) a foamed sample in BSE.

that is expressed as:

$$
\Delta G_{\text {het }}=\frac{16 \pi \gamma^{3}}{\Delta p^{2}} \frac{f(m, w)}{2}
$$

where $f(m, w)$ is a reduction factor and is a function of the nanoparticle shape and its interaction with the polymer matrix. ${ }^{39}$

As mentioned earlier, the main foaming occurred in the PP phase, and it seems that the location of the nanoparticles in this phase facilitates nucleation via a heterogeneous mechanism. To confirm this hypothesis, the distribution of the nanoclays in the unfoamed blend was monitored.

Generally in polymer blend nanocomposites, nanofiller localization is thermodynamically controlled, and the system tries to minimize its interfacial energy. In binary blends, such as PP/EPDM, nanoclays can be located in each individual phase or interface. The distribution of nanoclays in the blend can be estimated according to the Young's equation, based on the interfacial energies of the components, as follows ${ }^{40}$ :

$$
\omega_{a}=\frac{\gamma_{15 \mathrm{~A}, \mathrm{PP}}-\gamma_{15 \mathrm{~A}, \mathrm{EPDM}}}{\gamma_{\mathrm{PP} . \mathrm{EPDM}}}
$$

$\gamma_{15 \mathrm{~A} \text {,PP }}$ is the interfacial energy between the nanoclay and the PP, $\gamma_{15 \mathrm{~A}, \mathrm{EPDM}}$ is the interfacial energy between the nanoclay and the EPDM and $\gamma_{\text {PP,EPDM }}$ is that of PP and EPDM. $\omega_{\mathrm{a}}$ is the wetting parameter, which describes the wettability of the nanoclay by PP or EPDM. If the calculated $\omega_{\mathrm{a}}$ is $>1$, the nanoclays have better interaction with EPDM and can be found in the EPDM phase. If the calculated $\omega_{\mathrm{a}}$ is $<-1$, the nanoclays have stronger affinity to stay in the PP phase, and if $-1 \leqslant \omega_{\mathrm{a}} \leqslant 1$, the nanoclays accumulate at the interface. In principle, interfacial energies should be known to calculate the wetting coefficient $\left(\omega_{\mathrm{a}}\right)$. Some polymer/polymer interfacial energies can be found in the literature, but it is difficult to find data for special polymer/polymer or polymer/nanoclay systems. Interfacial energies can be calculated from surface-free energies, mostly via the harmonic mean equation (Eq. 5) or the geometric mean equation (Eq. 6). ${ }^{29}$

$$
\begin{aligned}
& \gamma_{12}=\gamma_{1}+\gamma_{2}-4\left[\frac{\gamma_{1}^{d} \gamma_{2}^{d}}{\gamma_{1}^{d}+\gamma_{2}^{d}}+\frac{\gamma_{1}^{p} \gamma_{2}^{p}}{\gamma_{1}^{p}+\gamma_{2}^{p}}\right] \\
& \gamma_{12}=\gamma_{1}+\gamma_{2}-2\left[\sqrt{\gamma_{1}^{d} \gamma_{2}^{d}}+\sqrt{\gamma_{1}^{p} \gamma_{2}^{p}}\right]
\end{aligned}
$$

Table 2 Calculated interfacial energies

\begin{tabular}{lccc}
\hline System & Temperature $\left({ }^{\circ} \mathrm{C}\right.$ ) & $\begin{array}{c}\text { Interfacial energy } \\
\mathrm{mN} \mathrm{m}^{-1} \text { (harmonic Eq) }\end{array}$ & $\begin{array}{c}\text { Interfacial energy } \\
\mathrm{mN} \mathrm{m}^{-1} \text { (geometric Eq) }\end{array}$ \\
\hline PP/EPDM & 190 & 0.323 & 0.162 \\
PP/15A & 190 & 3.66 & 0.09 \\
EPDM/15A & 190 & 5.02 & 0.49 \\
\hline
\end{tabular}

Abbreviation: PP/EPDM, polypropylene/ethylene propylene diene monomer.

where $\gamma_{1}$ and $\gamma_{2}$ denote the surface energies of components 1 and 2, respectively, whereas the $p$ and $d$ indices stand for the polar and disperse components of the surface energy, respectively. The surface energies were measured at room temperature $\left(25^{\circ} \mathrm{C}\right)$, and the temperature dependency $\left(-\frac{d \gamma}{d T}\right)$ was assumed to be 0.1 for nanoclay and 0.05 for polymers to obtain the values for the processing temperature. ${ }^{41}$ The surface free energies of solids consist of polar and nonpolar components. The polar component originates from hydrogen bonding and permanent and induced dipoles intermolecular forces, whereas the nonpolar component results from instantaneous moments.

Table 2 shows the interfacial energies that are calculated according to the harmonic mean equation and the geometric mean equation.

Finally, by substituting the obtained interfacial energies in Equation 4, the wetting parameter $\left(\omega_{\mathrm{a}}\right)$ was determined to be -4.2 via the harmonic equation and -2.4 via the geometric mean equation.

The calculated $\omega_{\mathrm{a}}$ coefficients for both the harmonic equation and the geometric equation are $<-1$, which clearly means that the nanoclays are more likely to be located in the PP phase.

It is well established that any change in the motion of polymer chains with temperature could be detected via DMTA analysis. Thus, it is of interest to address the nanoclay localization by means of this test. Figure 4 shows the tan $\delta$ of samples as a function of temperature.

As discussed above, PP/EPDM is a binary blend with two distinct phases; thus, in $\tan \delta$ patterns, two different peaks were observed that are attributed to EPEM and PP. During the glass-to-rubber transition, the polymer backbone starts to move, and this movement dissipates the energy of the chains. The wasted energy from viscous movement of the polymer chains is shown as the $\tan \delta$ peak in the DMTA results. Table 3 shows the $\tan \delta$ peak temperatures of the samples in detail. As observed for sample B1, the $\tan \delta$ peak temperatures are $-51.9^{\circ} \mathrm{C}$ and $5.1^{\circ} \mathrm{C}$ for the EPDM and PP phases, respectively. In nanocomposite 


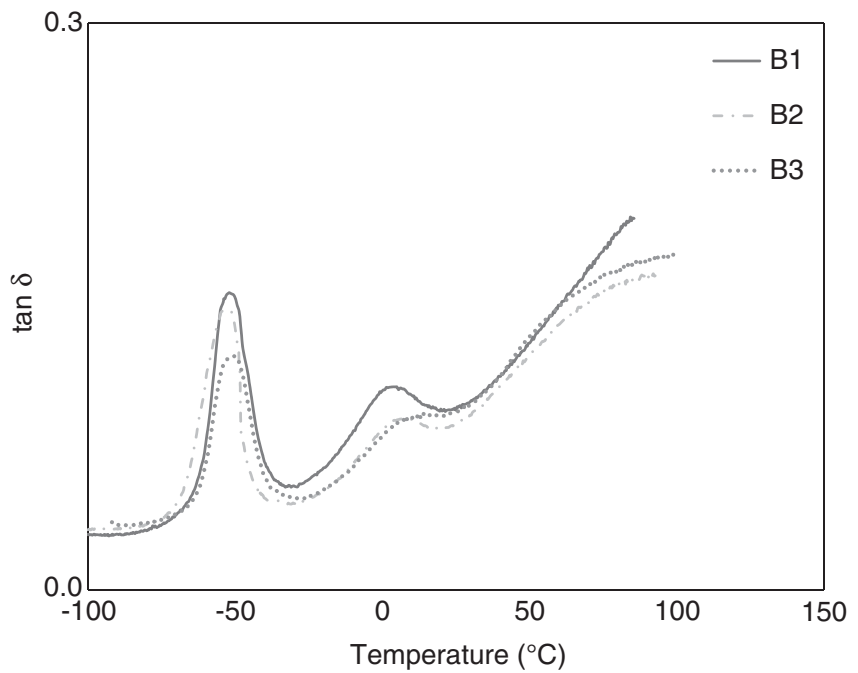

Figure 4 DMTA spectra of samples.

Table $3 \operatorname{Tan} \delta$ peak temperatures of the samples according to DMTA

\begin{tabular}{lccc}
\hline Samples & $\begin{array}{c}\text { Nanoclay loading } \\
(\text { phr })\end{array}$ & $\begin{array}{c}\text { Tan } \delta \text { peak for PP } \\
\text { phase }\left({ }^{\circ} \mathrm{C}\right)\end{array}$ & $\begin{array}{c}\text { Tan } \delta \text { peak for } \\
\left.\text { EPDM phase }{ }^{\circ} \mathrm{C}\right)\end{array}$ \\
\hline B1 & 0 & 5.1 & -51.9 \\
B2 & 2 & 8.3 & -52.9 \\
B3 & 4 & 10.7 & -51.4 \\
\hline
\end{tabular}

Abbreviations: DMTA, dynamic mechanical thermal analysis; EPDM, ethylene propylene diene monomer; PP, polypropylene.

samples, the $\tan \delta$ peaks that represent the PP phase are slightly shifted to higher temperatures, and thus the peak point is increased from $5.1^{\circ} \mathrm{C}$ (sample B1) to $10.7^{\circ} \mathrm{C}$ (sample B3), but in the EPDM phase, it has only a marginal change. Polymer chains need free volume to have long-range mobility, and by temperature increments, the free volume is increased at the glass-transition temperature (close to the $\tan \delta$ peak). The existing nanoparticles occupy free volumes and reduce the mobility of the surrounding polymer chains. Hence, more energy should be consumed for the movement of chains, and this causes an increase in the $\tan \delta$ peak temperature. According to the DMTA results presented in Table 3, nanoclays have more influence on the PP phase than EPDM, and it means that they localize mostly in the PP matrix, which corresponds to the results predicted by the wetting coefficients.

AFM is another suitable technique to study the micro- and nanostructure of the nanocomposite blends. The height image of the sample B2 microtomed surface is illustrated in Figure 5a. In this picture, the dark regions are the EPDM dispersed phase, the brown ones are related to the PP matrix and the yellowish-white parts represent nanoclays. For further analysis, the cross-line profile scans are illustrated as spectra in Figure 5b. These cross-lines show some irregularities due to the surface roughness of the blend. However, when the lines pass through the yellowish-white regions, sharp peaks appear in the spectra, which could be an indication of the existence of nanofillers. As seen in the figure, the size of these parts is on the order of $200 \mathrm{~nm}$. Comparing the size of the white regions in the AFM height image and the average length of the plate-like nanoclays (100$200 \mathrm{~nm}$ ), one can conclude that these yellowish-white parts are the individual nanoclay layers that laid in the PP. Visual observation via a

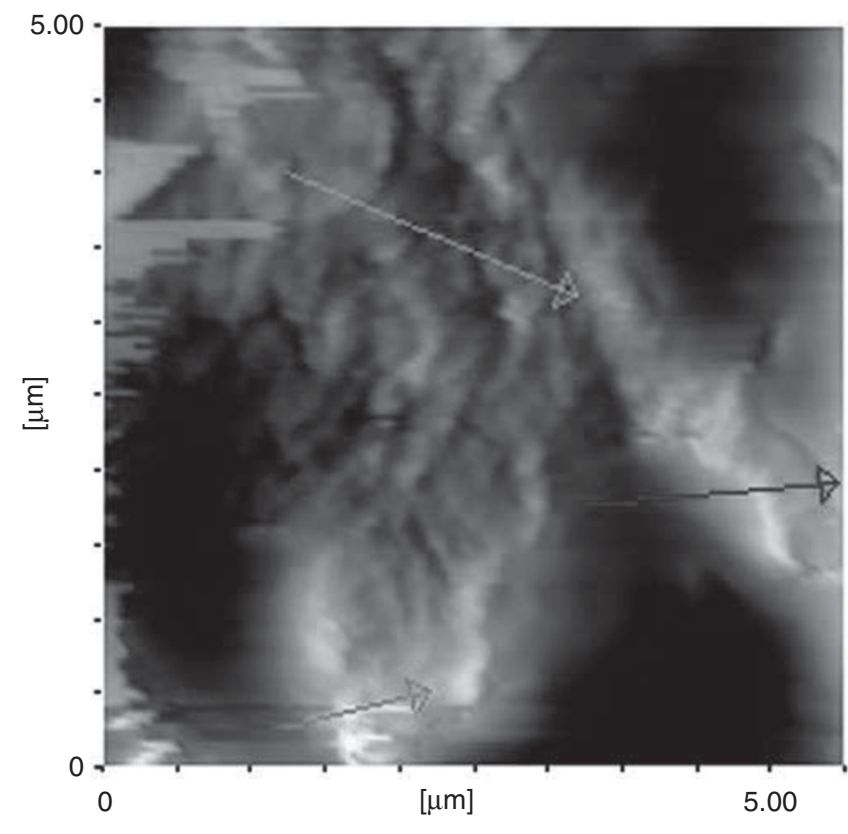

b

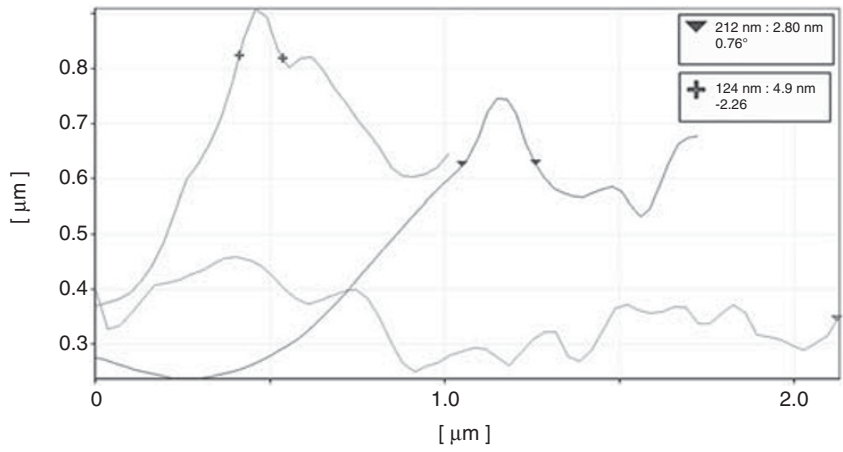

Figure 5 The height image of (a) sample B2 and (b) the cross-line scan-line profile.

AFM topographic analysis allows us to conclude that the nanoclays are distributed in the PP phase.

The wetting properties of the blend and the dynamic mechanical test, as well as AFM measurements, revealed that the nanoclays are located primarily in the PP phase. To confirm these results, TEM imaging was performed. Figure 6 shows the TEM micrograph of the nanocomposite blend. The white parts of the image correspond to the EPDM dispersed domains, the gray parts are the PP matrix and the black lines are the Cloisite 15A layers. As observed in the image, nanosilicate layers are separated, and the exfoliated state is attained. Moreover, it is evident from the image that the nanoclays are dispersed in the PP matrix.

Another target of this study was to evaluate whether the nanoclays have an influence on foam nucleation. It was mentioned that foaming occurs in the PP phase and that the nanoclays should be distributed in the PP to facilitate the nucleation step. The cell density and the average cell size of the foamed samples, the main characteristics of microcellular foam, were measured and are reported in Table 4 . The cell density significantly increases when only 2 phr of nanoclay was added, and it became two times more than that of the non-filled foam. In the case of $4 \mathrm{phr}$ nanoclay loading, the same trend is observed. Similar results have been obtained for the average cell diameter. 


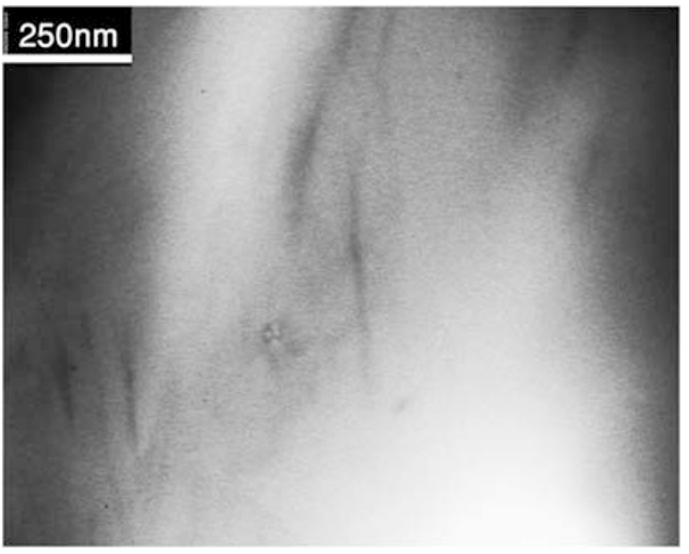

Figure 6 TEM micrograph of the nanocomposite blend.

Table 4 Cell density and the average cell diameter of foamed samples

\begin{tabular}{lcccc}
\hline Sample & $\begin{array}{c}\text { Nanoclay } \\
\text { content (Phr) }\end{array}$ & $\begin{array}{c}\text { Foaming } \\
\text { pressure }(P s i)\end{array}$ & $\begin{array}{c}\text { Cell density } \\
(\text { cells cm }\end{array}$ & $\begin{array}{c}\text { Average cell } \\
\text { diameter }(\mu \mathrm{m})\end{array}$ \\
\hline B1 & 0 & 1400 & $4.46 \mathrm{E} 9$ & 2.82 \\
B2 & 2 & 1400 & $8.7 \mathrm{E} 9$ & 1.70 \\
B3 & 4 & 1400 & $1.44 \mathrm{E} 10$ & 1.41 \\
\hline
\end{tabular}

\section{CONCLUSIONS}

In this study, a quick heating method was used to prepare PP/EPDM/ organoclay microcellular foam. The foaming temperature and morphological observation showed that foaming mainly occurs in the PP phase, and it appears that the location of the nanoparticles in this phase facilitated nucleation via a heterogeneous nucleation mechanism. The distribution of nanoclays and their effect on foam morphology were also discussed. The results revealed that nanoclays have more interaction with PP and locate primarily in the PP phase. Finally, cell analysis showed that an improved foam structure was achieved by adding only small amounts of nanoclays to the blend.

\section{ACKNOWLEDGEMENTS}

We are very grateful for the financial support they received from the Iran National Science Foundation (INSF).

1 Martini-Vvedensky, J., Suh, N. \& Waldman, F. Microcellular closed cell foams and their method of manufacture. US Patent 4473665 (1984).

2 Doroudiani, S., Park, C. B. \& Kortschot, M. T. Effect of the crystallinity and morphology on the microcellular foam structure of semicrystalline polymers. Polym. Eng. Sci. 36, 2645-2662 (1996).

3 Kumar, V. Microcellular polymers: novel materials for the 21st century. Prog. Rubber Plast. Technol. 9, 54-70 (1993).

4 Reglero Ruiz, J., Viot, P. \& Dumon, M. Microcellular foaming of polymethylmethacrylate in a batch supercritical $\mathrm{CO} 2$ process: Effect of microstructure on compression behavior. J. Appl. Polym. Sci. 118, 320-331 (2010).

5 Arora, K. A., Lesser, A. J. \& McCarthy, T. J. Preparation and characterization of microcellular polystyrene foams processed in supercritical carbon dioxide. Macromolecules 31, 4614-4620 (1998).

6 Sumarno, Y., Takishima, S. \& Masuoka, H. Production of polystyrene microcellular foam plastics and a comparison of late-and quick-heating. J. Appl. Polym. Sci. 77, 23832395 (2000).

7 Han, X., Koelling, K., Tomasko, D. \& Lee, L. Continuous microcellular polystyrene foam extrusion with supercritical CO2. Polym. Eng. Sci. 42, 2094-2106 (2002).
8 Park, C. B. \& Suh, N. P. Filamentary extrusion of microcellular polymers using a rapid decompressive element. Polym. Eng. Sci. 36, 34-48 (1996).

9 Kumar, V. \& Weller, J. Polymeric Foams, ch. 7, 101-114 (American Chemical Society, 1997).

10 da Costa, H. M., Ramos, V. D., da Silva, W. S. \& Sirqueira, A. S. Analysis and optimization of polypropylene (PP)/ethylene-propylene-diene monomer (EPDM)/scrap rubber tire (SRT) mixtures using RSM methodology. Polym. Test. 29, 572-578 (2010).

11 da Silva, A. L. N. \& Coutinho, F. M. B. Some properties of polymer blends based on EPDM/PP. Polym. Test. 15, 45-52 (1996).

12 Wong, S., Naguib, H. E. \& Park, C. B. Effect of processing parameters on the cellular morphology and mechanical properties of thermoplastic polyolefin (TPO) microcellular foams. Adv. Polym. Technol. 26, 232-246 (2007).

13 Nemoto, T., Takagi, J. \& Ohshima, M. Control of bubble size and location in nano/ microscale cellular poly (propylene)/rubber blend foams. Macromol. Mater. Eng. 293, 574-580 (2008).

14 Nemoto, T., Takagi, J. \& Ohshima, M. Nanoscale cellular foams from a poly (propylene) rubber blend. Macromol. Mater. Eng. 293, 991-998 (2008).

15 Atsushi Tsuchiya, H. T., Kikuchi, T., Takahashi, T. \& Koyama, K. Influence of filler types and contents on foaming structures in ABS microcellular foams. Polym. J. 39, 514523 (2007).

16 Urbanczyk, L., Calberg, C., Detrembleur, C., Jérôme, C. \& Alexandre, M. Batch foaming of SAN/clay nanocomposites with scCO2: a very tunable way of controlling the cellular morphology. Polymer 51, 3520-3531 (2010).

17 Lee, Y. H., Wang, K. H., Park, C. B. \& Sain, M. Effects of clay dispersion on the foam morphology of LDPE/clay nanocomposites. J. Appl. Polym. Sci. 103, 2129-2134 (2007).

18 Shen, J., Zeng, C. \& Lee, L. Synthesis of polystyrene-carbon nanofibers nanocomposite foams. Polymer 46, 5218-5224 (2005).

19 Zhu, B., Zha, W., Yang, J., Zhang, C. \& Lee, L. J. Layered-silicate based polystyrene nanocomposite microcellular foam using supercritical carbon dioxide as blowing agent. Polymer 51, 2177-2184 (2010).

20 Riahinezhad, M., Ghasemi, I., Karrabi, M. \& Azizi, H. Morphology and tensile properties of crosslinked nanocomposite foams of low density polyethylene and poly (ethylene co vinyl acetate) blends. J. Vinyl. Addit. Technol. 16, 229-237 (2010).

21 Zhai, W., Yu, J., Wu, L., Ma, W. \& He, J. Heterogeneous nucleation uniformizing cell size distribution in microcellular nanocomposites foams. Polymer 47, 7580-7589 (2006).

22 Ema, Y., Ikeya, M. \& Okamoto, M. Foam processing and cellular structure of polylactide-based nanocomposites. Polymer 47, 5350-5359 (2006).

23 Yokoyama, H. \& Sugiyama, K. Nanocellular structures in block copolymers with CO2philic blocks using $\mathrm{CO} 2$ as a blowing agent: Crossover from micro-to nanocellular structures with depressurization temperature. Macromolecules 38, 10516-10522 (2005).

24 Mehrabzadeh, M. \& Kamal, M. R. Polymer clay nanocomposites based on blends of polyamide 6 and polyethylene. Can. J. Chem. Eng. 80, 1083-1092 (2002).

25 Lipatov, Y. S. Polymer blends and interpenetrating polymer networks at the interface with solids. Prog. Polym. Sci. 27, 1721-1801 (2002).

26 Argon, A. \& Cohen, R. Toughenability of polymers. Polymer 44, 6013-6032 (2003).

27 Hong, J. S., Namkung, H., Ahn, K. H., Lee, S. J. \& Kim, C. The role of organically modified layered silicate in the breakup and coalescence of droplets in PBT/PE blends. Polymer 47, 3967-3975 (2006).

28 Fenouillot, F., Cassagnau, P. \& Majesté, J. C. Uneven distribution of nanoparticles in immiscible fluids: Morphology development in polymer blends. Polymer 50, 13331350 (2009).

29 As'habi, L., Jafari, S., Baghaei, B., Khonakdar, H., Pötschke, P. \& Böhme, F. Structural analysis of multicomponent nanoclay-containing polymer blends through simple model systems. Polymer 49, 2119-2126 (2008).

30 Huitric, J., Ville, J., Médéric, P., Moan, M. \& Aubry, T. Rheological, morphological and structural properties of PE/PA/nanoclay ternary blends: Effect of clay weight fraction. J. Rheol. 53, 1101 (2009).

31 Calcagno, C., Mariani, C.. Teixeira, S. \& Mauler, R. The role of the MMT on the morphology and mechanical properties of the PP/PET blends. Composites Sci. Technol. 68, 2193-2200 (2008).

32 Han, X., Zeng, C., Lee, L., Koelling, K. \& Tomasko, D. Extrusion of polystyrene nanocomposite foams with supercritical CO2. Polym. Eng. Sci.43, 1261-1275 (2003).

33 Lee, L., Koelling, K., Tomasko, D., Han, X. \& Zeng, C. Polymer nanocomposite foams. US patent 6759446 (2002).

34 Khorasani, M. M., Ghaffarian, S. R., Babaie, A. \& Mohammadi, N. Foaming BEHAVIOR and cellular structure of microcellular HDPE nanocomposites prepared by a high temperature process. J. Cell. Plast. 46, 173-190 (2010).

35 Riahinezhad, M., Ghasemi, I., Karrabi, M. \& Azizi, H. Morphology and tensile properties of crosslinked nanocomposite foams of low density polyethylene and poly (ethylene co vinyl acetate) blends. J. Vinyl Addit. Technol. 16, 229-237 (2010).

36 Xu, Z., Jiang, X., Liu, T., Hu, G., Zhao, L., Zhu, Z. \& Yuan, W. Foaming of polypropylene with supercritical carbon dioxide. J. Sup. Flu. 41, 299-310 (2007).

37 Reverchon, E. \& Cardea, S. Production of controlled polymeric foams by supercritical C02. J. Sup. Flu. 40, 144-152 (2007).

38 Colton, J. \& Suh, N. Nucleation of microcellular foam: theory and practice. Polym. Eng. Sci. 27, 500-503 (1987).

39 Fletcher, N. Size effect in heterogeneous nucleation. J. Chem. Phy. 29, 572 (1958).

40 Sumita, M., Sakata, K., Asai, S., Miyasaka, K. \& Nakagawa, H. Dispersion of fillers and the electrical conductivity of polymer blends filled with carbon black. Polym. Bull. 25, 265-271 (1991).

41 Lewin, M., Mey Marom, A. \& Frank, R. Surface free energies of polymeric materials, additives and minerals. Polym. Adv. Technol. 16, 429-441 (2005). 